\title{
Estructura del quiste hidatídico producido por Echinococcus oligarthrus en el hospedero intermediario Proechimys c.f. guairae (rata espinosa) en Casanare, Colombia
}

\author{
Gerzain Rodríguez ${ }^{1}$, Margarita Tamayo ${ }^{2}$, Jorge Boshell ${ }^{3}$ \\ ' Laboratorio de Patologia, Instituto Nacional de Salud; Facultad de Medicina, Universidad Nacional de Colombia, Bogotá. \\ D.C., Colombia \\ 2 Laboratorio de Virología, Instituto Nacional de Salud, Bogotá, D.C., Colombia \\ ${ }^{3}$ Dirección General, Instituto Nacional de Salud, Bogotá, D.C., Colombia
}

\begin{abstract}
La equinococosis es un parasitismo grave producido en el hombre y en los animales por larvas de tenias del género Echinococcus que se desarrollan en el hígado, el pulmón, el bazo y en otras vísceras y tejidos. De las cuatro tenias del género Echinococcus, tres se presentan en Suramérica: E. granulosus, E. vogeli y E. oligarthrus. En Colombia se han informado casos en humanos y en animales cuyo agente etiológico más frecuente es $E$. vogeli. En este trabajo presentamos la estructura macroscópica, microscópica y de microscopía electrónica de barrido de quistes hidatídicos múltiples y de sus protoescólices encontrados en un Proechimys c.f. guairae o rata espinosa, capturado en la vereda La Plata del municipio de Pore, Casanare, durante la búsqueda de reservorios del virus de la encefalitis equina venezolana. En la autopsia del animal se encontraron quistes múltiples en el hígado, el bazo y el pulmón, la gran mayoría fértiles. Están constituidos por una pared franjeada que origina cápsulas prolígeras dentro de las cuales están los protoescólices. El protoescólex es el escólex inmaduro del parásito adulto formado por cuatro ventosas y un rostelo con ganchos, cuyo tamaño y morfología corresponden con las medidas de $E$. oligarthrus. Ilustramos las características morfológicas de las larvas, el desarrollo de los protoescólices y revisamos las características de la equinococosis en Colombia.
\end{abstract}

Palabras clave: quiste hidatídico, equinococosis en Colombia, Proechimys c.f. guairae, Echinococcus oligarthrus

\section{Structure of hydatid cyst due to Echinococcus oligarthrus in the intermediary host Proechimys c.f. guairae in Casanare, Colombia}

Infection by larvae of Echinococcus parasites is a serious human and animal disease known as echinococcosis or hydatid disease. The cystic lesions may damage different organs, mainly the liver, spleen and lungs. E. granulosus, E. vogeli and E. oligarthrus have been described in South America. In Colombia, hydatid disease both in humans and animals is produced mainly by $E$. vogeli. In this paper, we describe in detail the morphological structure of hydatid polycysts found in a rodent, Proechimys c.f guairae, captured in La Plata, in Pore municipality, Casanare department, in the eastern plains of the country, during studies carried out on Venezuelan Equine Encephalitis virus reservoirs. The autopsy revealed multiple cysts in liver, spleen and lungs. Most of them were mature cysts with large number of protoscolices, whose size and that of its hooks, corresponded with those described for Echinococcus oligarthrus. We illustrate and describe the morphological characteristics of these larvae, using both light and scanning electron microscopes. We also briefly review the observations made on echinococcosis in Colombia.

Key words: Hydatidic cyst, echinococcosis in Colombia, Proechimys c.f. guairae, Echinococcus oligarthrus

Correspondencia:

G. Rodriguez, Laboratorio de Patologia, Instituto Nacional de Salud, Apartado aéreo 80334, Bogotá, D.C., Colombia. e-mail: grodriguez@hemagogus.ins.gov.co

Recibido: 11/04/00; aceptado: 08/09/00 
La equinococosis es un parasitismo producido por tenias y larvas de los céstodos del género Echinococcus. Las tenias adultas son diminutas, de 2 a $6 \mathrm{~mm}$ de longitud; se localizan en el intestino delgado de cánidos y félidos, hospederos definitivos de los parásitos $(1,2)$. Sus huevos son eliminados en la materia fecal y al ser ingeridos por los huéspedes intermediarios como ovejas, cabras, varias especies de roedores o por las personas, originan oncosferas en su intestino, embriones hexacanto que penetran las criptas del yeyuno e ileon superior y migran por el torrente sanguíneo a diversos órganos: hígado, riñón, pulmón, bazo, cerebro, órbita, huesos o músculos $(1,2)$. El desarrollo subsiguiente de la larva en estos órganos origina quistes que crecen $1 \mathrm{~mm} / \mathrm{mes}$, los cuales, con el tiempo, pueden ocasionar la muerte del huésped intermediario por acción mecánica, alérgica o tóxica. A estos quistes se les conoce como hidatídicos y la enfermedad que producen como hidatidosis o equinococosis. Los hospederos definitivos adquieren el parásito al consumir las vísceras del huésped intermediario, en el cual se desarrolla el quiste hidatídico con una multitud de protoescólices infectantes $(1,2)$.

Hay cuatro especies de tenias dentro del género Echinococcus: dos originalmente holárticas representadas por E. granulosus y E. multilocularis y dos neotropicales, E. vogeli y E. oligarthrus (1). Tres de éstas se presentan en Suramérica: $E$. oligarthrus y $E$. vogeli son especies nativas y $E$. granulosus fue introducida de Europa a comienzos del siglo XVI (3). Morfológicamente, las especies pueden diferenciarse en la actualidad por múltiples características: estado adulto del céstodo, características de la larva, tamaño de las cápsulas prolígeras y de los protoescólices y, principal- mente, por el tamaño, la forma y las proporciones de las partes de los ganchos rostelares de los protoescólices $(3,4)$.

En Colombia, se ha confirmado la presencia de E. granulosus, E. vogeli y E. oligarthrus (5-7). La larva del primero de ellos es quística y se ha demostrado en personas emigrantes de Europa y de Argentina donde esta especie es endémica $(6,8)$. E. vogeli es el principal causante de la equinococosis humana en Colombia; su larva es poliquística (6). En este país, E. oligarthrus, también con larvas poliquísticas, se ha demostrado en huéspedes animales, pero no como causante de enfermedad humana, lo cual sí ha ocurrido en Venezuela, Brasil y Surinam (9-11). La infección por larvas y adultos de estos céstodos en Colombia, se ilustra en el cuadro 1 $(2,7)$.

El objetivo de este trabajo es presentar la morfología macroscópica, microscópica y de microscopía electrónica de barrido, del quiste hidatídico identificado como de $E$. oligarthrus, en un Proechimys c.f. guairae capturado en el municipio de Pore, departamento de Casanare, Colombia, durante un estudio de reservorios del virus de la encefalitis equina venezolana (EEV).

\section{Materiales y métodos}

El área de estudio se encuentra ubicada a 190 msnm, en la finca La Guhiva, vereda La Plata, municipio de Pore, Casanare (Colombia), con coordenadas: $5^{\circ} 35^{\prime} 12,9^{\prime \prime} \mathrm{N}$ y $71^{\circ} 54^{\prime} 30,3^{\prime \prime} \mathrm{O}$. Dentro del proyecto de EEV desarrollado por el Instituto Nacional de Salud, se realizó una salida de campo a este lugar, entre el 14 y el 25 de septiembre de 1999 y se capturaron eventuales vectores y reservorios del virus de la EEV en un

Cuadro 1. Especies de Echinococcus con sus hospederos definitivos e intermediarios en Colombia (7).

\begin{tabular}{lll}
\hline Especie & Hospedero definitivo & Hospedero intermediario \\
\hline E. granulosus* & $\begin{array}{l}\text { No se ha demostrado } \\
\text { Speothos venaticus (perro de monte) } \\
\text { E. vogeli }\end{array}$ & $\begin{array}{l}\text { Humanos } \\
\text { Cuniculus paca (paca) }\end{array}$ \\
& $\begin{array}{l}\text { Felis onça (jaguar) } \\
\text { Felis concolor (puma) }\end{array}$ & $\begin{array}{l}\text { Proechimys spp. (ratón de campo) } \\
\text { Felis yagouaroundi (yaguarundi) } \\
\text { Felis pardalis (ocelote) }\end{array}$ \\
& Cuniculus paca (paca) \\
\hline
\end{tabular}

${ }^{*} E$. granulosus ha ocurrido solamente en inmigrantes humanos $(6,8)$. 
bosque de galería ubicado en cercanías del río Curama. Uno de los ejemplares capturados fue un Proechimys c.f. guairae, macho joven, grande y de aspecto vigoroso, que había sido seleccionado como semental de la colonia experimental (figura 1). El animal murió el día de su captura en la jaula en la cual se transportaba; dos horas después de muerto, se realizó la autopsia y los órganos se fijaron en formol neutro al $10 \%$.

Los tejidos se incluyeron en parafina y los cortes seriados se tiñeron con hematoxilina eosina (HE), ácido peryódico de Schiff (PAS) y Fite Faraco (FF).

Algunos fragmentos se incluyeron en resinas epóxicas y se estudiaron en cortes de $1 \mu \mathrm{m}$ de espesor teñidos con azul de toluidina, por la técnica de microscopía óptica de alta resolución (MOAR).

La observación de los ganchos de los protoescólices se realizó en fresco, en microscopía de contraste de fase y con coloración de FF a partir de raspado de los quistes, comprimidos entre lámina y laminilla.

Los ganchos se midieron en su longitud total, incluyendo la de la hoja y la del mango por separado, con objetivo de $100 \mathrm{x}$, utilizando un microscopio Nikon y el programa de análisis de imágenes Lucía M. Las mediciones se expresaron en micras y el promedio y la desviación estándar se encuentran entre paréntesis después de cada medida.

Partes de un quiste fijado en formol neutro al 10\% se procesaron para microscopía electrónica de

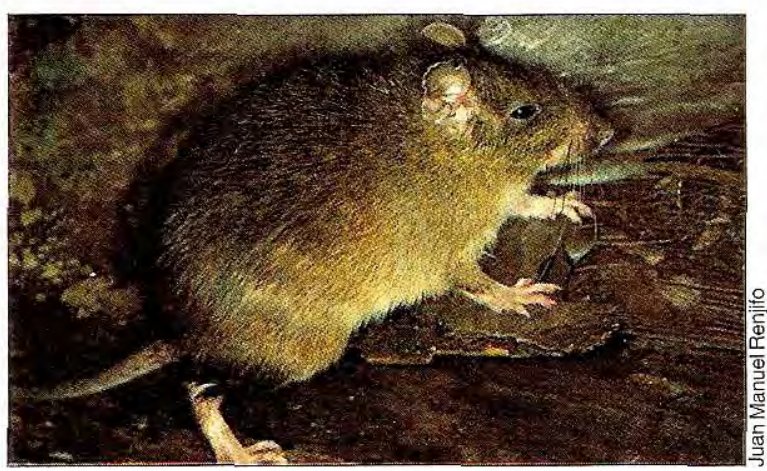

Figura 1. Proechimys spp. o rata espinosa barrido, con desecación de punto crítico y sombreado con oro.

La identificación de la especie se realizó mediante las variaciones en la forma y la longitud de los ganchos, así como en la proporción de la hoja y el mango de éstos, basándonos en mediciones informadas en la literatura $(3,4)$.

\section{Resultados}

\section{Macroscopía}

En la autopsia del animal se observaron múltiples nódulos blanco-amarillentos blandos y renitentes en la superficie del hígado, algunos colapsados; al corte mostraron aspecto quístico con un contenido líquido bianco-amarillento, tamaño entre 5 y $12 \mathrm{~mm}$ de diámetro mayor y pared delgada, blanquecina, finamente granular en su interior (figuras 2, 3). En el bazo, se observaron múltiples formaciones quísticas semejantes a las del hígado y en el pulmón se demostró un quiste de $1 \mathrm{~cm}$ de diámetro.

\section{Histopatología}

Los quistes tienen origen parasitario, con la morfología del quiste hidatídico $(1,2)$. Consisten de una cápsula conjuntiva del huésped sobre la cual se apoya la membrana lamelar acelular del parásito que sirve de sustento a las células cuboidales altas y claras, que forman la capa germinativa. Esta capa celular da origen a prolongaciones tenues que constituyen el origen y el revestimiento de las cápsulas prolígeras, de las cuales se desprenden multitud de estructuras ovoides o redondeadas, denominadas protoescólices, unidas por un delgado tallo a la cápsula prolígera (figuras 4-7).

Las cápsulas prolígeras tienen forma redondeada con diámetro menor de 160,6 - 817,6 $\mu \mathrm{m}(\overline{\mathrm{x}}=333,1$ $\pm 117,4$ ) y diámetro mayor de 204,4-1.036,6 $\mu \mathrm{m}$ $\bar{\top} \mathrm{X}=411,4 \pm 161,6)$. En su interior, los protoescólices tienen forma de campana o de pera y miden: diámetro menor $79,2-108 \mu \mathrm{m}(\bar{x}=91,9 \pm 8,7)$ y diámetro mayor 103-134,4 $\mu \mathrm{m}(\bar{x}=122,3 \pm 8,5)$. Su estructura está constituida por un tallo germinal desprendido de la membrana prolígera (figuras 8 y 9), una gruesa cubierta membranosa eosinófila, PAS positiva, que se invagina en el extremo opuesto al tallo con repliegues profundos que 


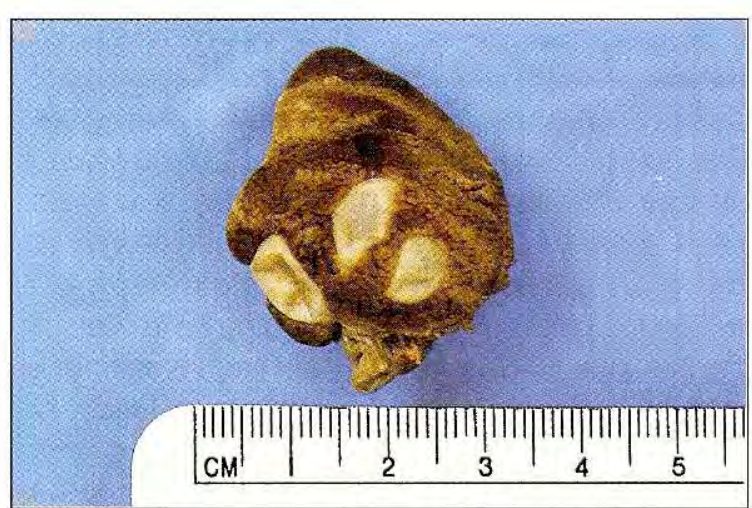

Figura 2. Hígado de Proechimys c.f. quairae con 3 quistes colapsados sobre su superficie, en los que resalta la pared característica, delgada, amarillenta y lisa.

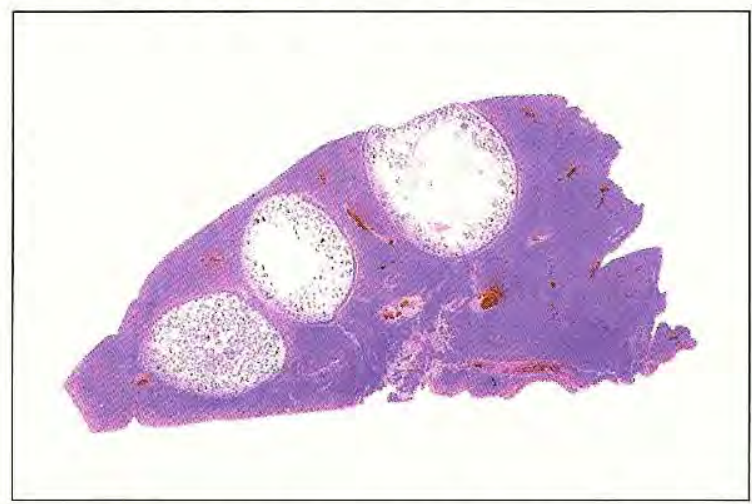

Figura 4. Panorámica microscópica de 3 quistes hepáticos; se aprecia la cápsula, las membranas prolígeras y la multitud de diminutos protoescólices. HE, 1X.

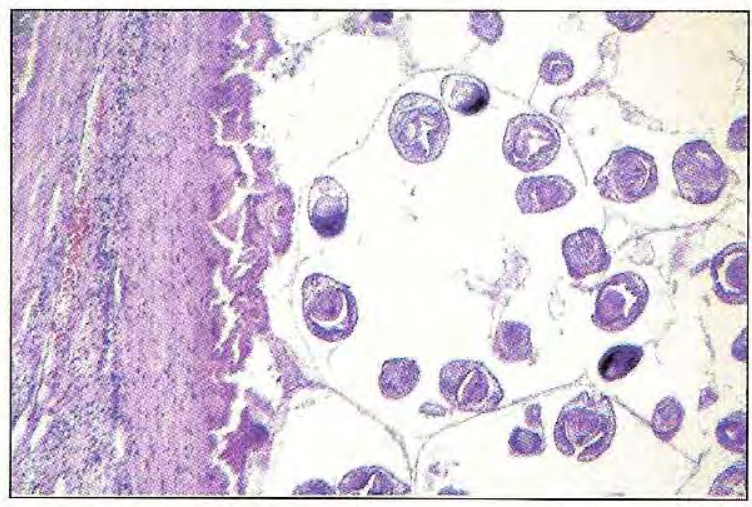

Figura 6. El tejido hepático está separado del quiste por una lámina fibroblástica con algunos mononucleares del huésped; sobre esta lámina de colágeno se apoya la capa lamelar del parásito, un tanto desflecada, seguida de un estrato celular o germinativo, del cual salen tenues ramificaciones que limitan las cápsulas prolígeras; dentro de éstas se forman los protoescólices. HE, 10X.

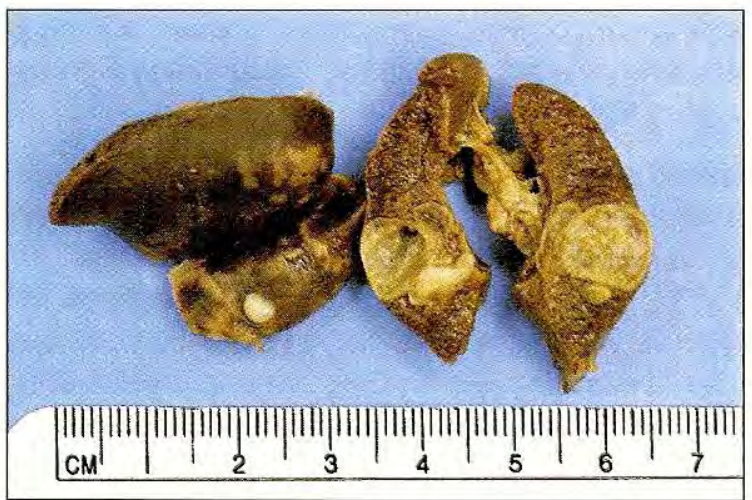

Figura 3. Al corte se aprecia la delgada pared del quiste con su superficie interior finamente granular.

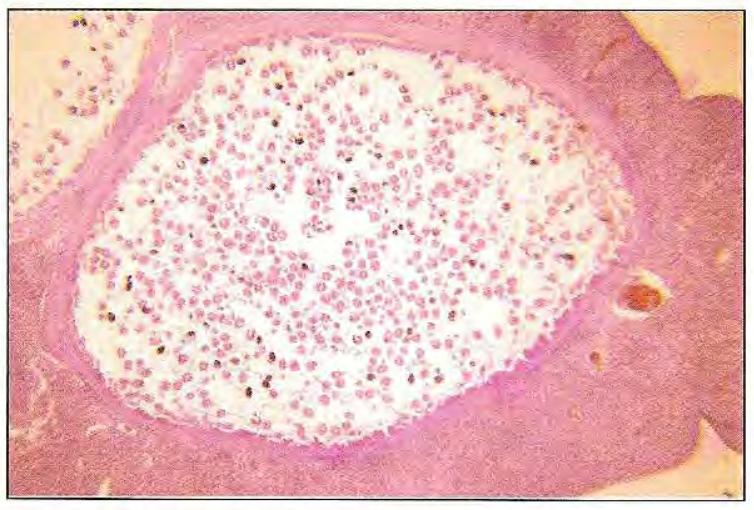

Figura 5. Quiste hepático con cápsula tenue, membrana germinativa, cápsulas prolígeras y enorme número de protoescólices; cada uno de éstos dará lugar a una tenia adulta en el intestino del huésped definitivo; el tejido hepático vecino al quiste aparece normal. $\mathrm{HE}, 1,5 \mathrm{X}$.

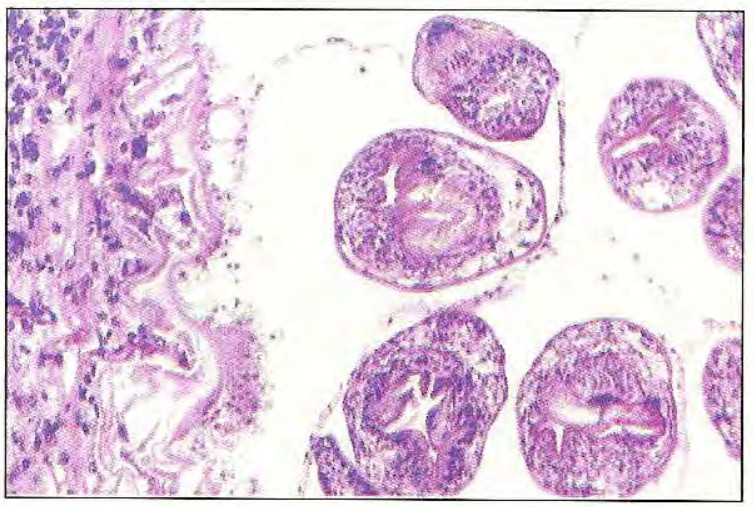

Figura 7. En este quiste hidatídico del hígado se observa la membrana conjuntiva del huésped con mononucleares, la membrana lamelar y festoneada del parásito, con una cubierta epitelial interna o capa germinal, de células altas y vacuoladas, las tenues membranas prolígeras y pocos protoescólices. HE, 32X. 
constituyen una cubierta para una masa cónica y ovoide central en donde están los ganchos (figuras 8,10 y 11).

Estos, dispuestos en dos filas, presentan una coloración amarillo-transparente a la HE y son ácido-resistentes con la coloración de FF (figuras 8 y 11). Como el número de protoescólices es enorme y su tamaño es considerable, es posible cortarlos en muchas incidencias, que revelan sólo algunos aspectos de su morfología. La microscopía electrónica de rastreo da una buena idea de su morfología tridimensional (figuras 12 y 13).

Pocos quistes consisten sólo de las capas lamelar y germinativa, sin formación de las cápsulas

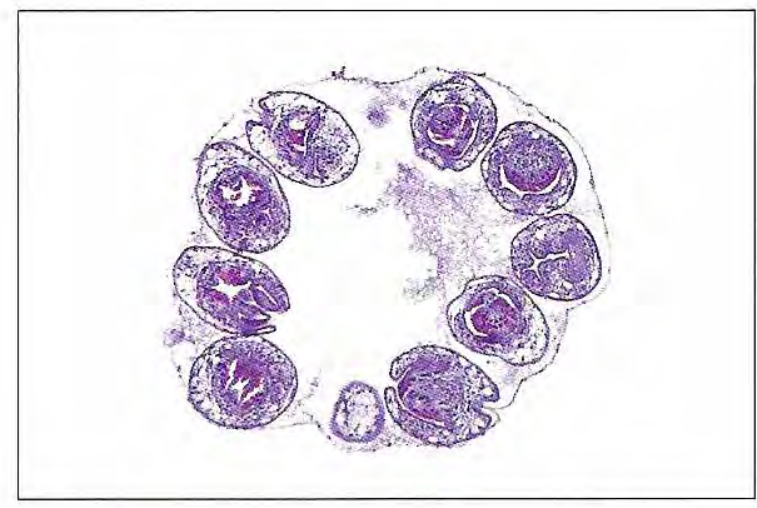

Figura 8. Cápsula prolígera que origina 10 protoescólices en dos de los cuales se aprecia el deigado tallo que los une a la cápsula; los ganchos de los protoescólices son ácidoalcohol resistentes. Fite-Faraco, 20X.

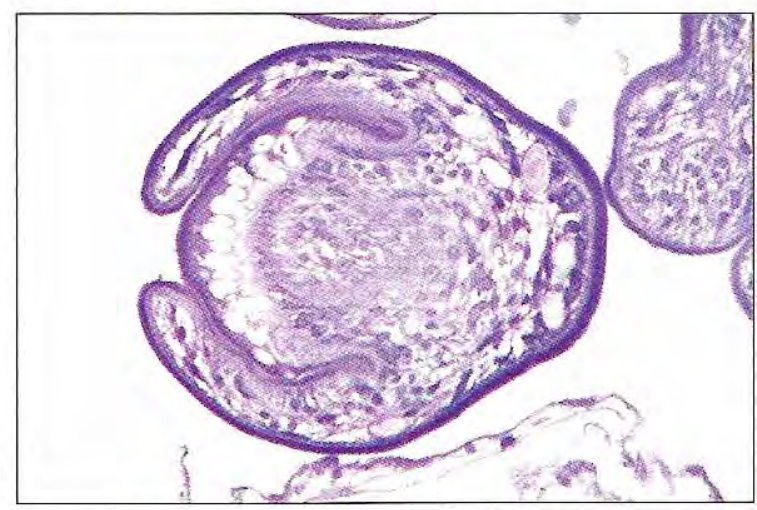

Figura10. Protoescólex preparado de manera semejante al de la figura anterior; resalta su cubierta densa que se invagina en el extremo superior para cubrir la cúpula en donde están los ganchos, claros y poco teñidos. Azul de toluidina, $40 \mathrm{X}$. prolígeras y sin presencia de protoescólices; son quistes estériles que se vieron en el bazo y no en los otros órganos. La mayoría de los quistes del bazo tiene su pared intensamente permeada por células inflamatorias: neutrófilos, linfocitos, plasmocitos y sólo ocasionales eosinófilos; resalta una gran cantidad de células gigantes multinucleadas que fagocitan fragmentos de la cápsula (figuras 14 y 15). La inflamación llega a romper el quiste y a liberar los protoescólices al tejido, en donde la infiltración celular se hace más acentuada. Lo anterior conduce a reabsorber algunos quistes, proceso que se acompaña de amplias zonas de necrosis eosinofílica de aspecto caseoso con cariorrexis y fragmentos del parásito

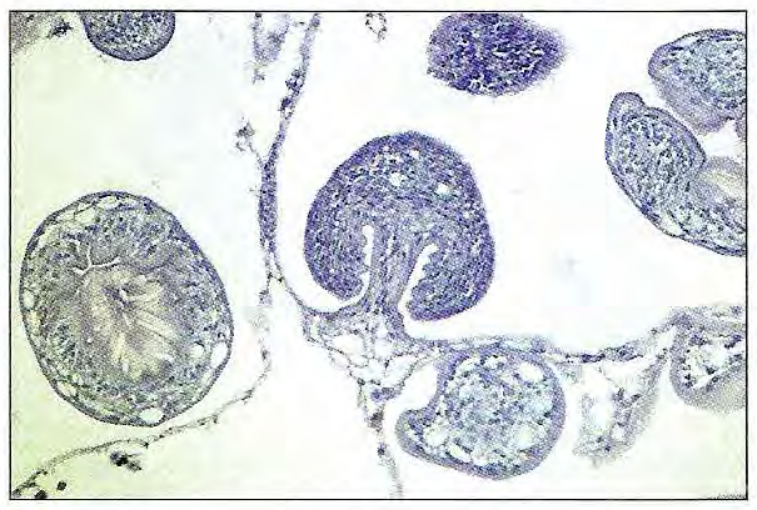

Figura 9. Comienzo de la formación de un protoescólex a partir de la membrana de la cápsula prolígera, a la cual está unido por un tallo delgado; corte de 1 micra de espesor a partir de tejido incluido en resinas. Azul de toluidina, 40X.

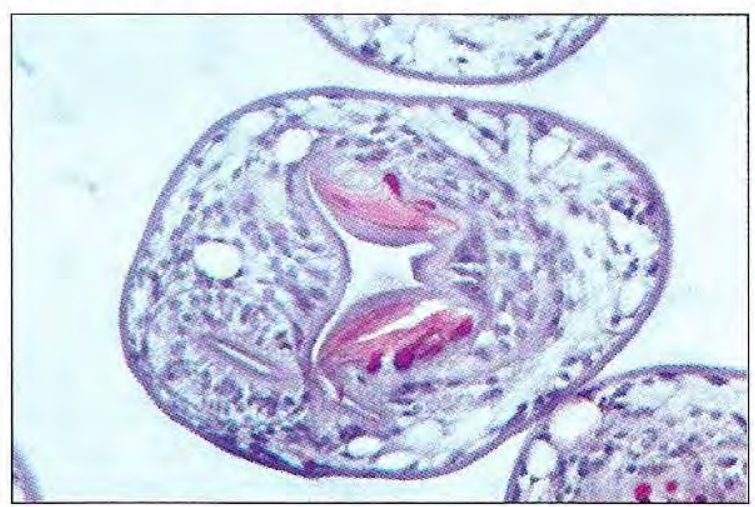

Figura 11. Protoescólex; los ganchos son rojos, ácidoalcohol resistentes. Fite-Faraco, 80X. 

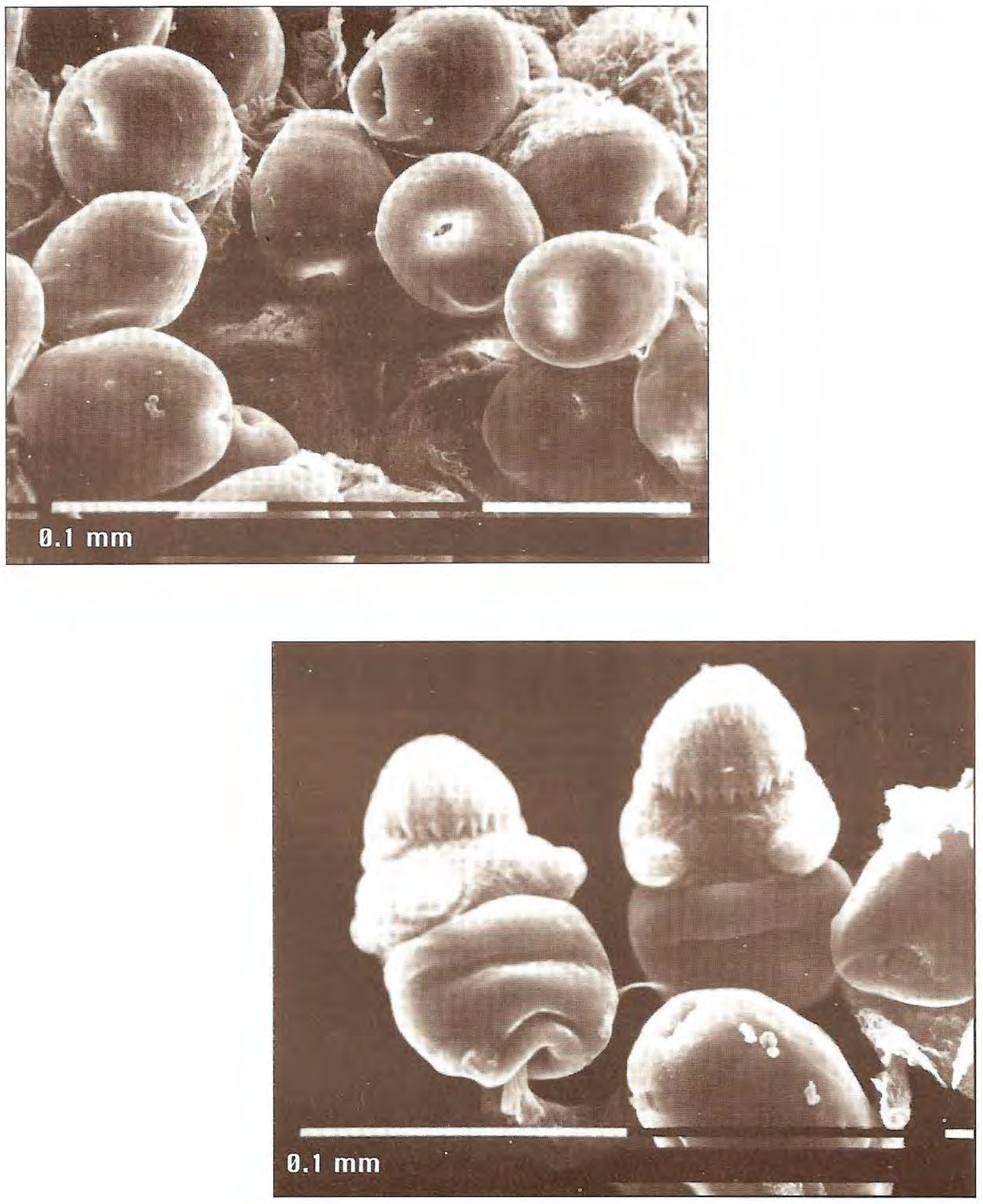

Figuras 12 y 13. Electromicrografías de barrido de protoescólices; se demuestra su morfología piriforme o de campana, con un hueco o tallo fino que los une a la membrana prolígera; la base de los ganchos se insinúa en la figura 13 . Escala: 0,1 mm. 
(figura 14). El aspecto festoneado y lamelar de la membrana externa remanente del parásito ofrece una imagen típica, propia del género Echinococcus y, por tanto, con valor diagnóstico definitivo (1) (figura 15).

\section{Descripción de los ganchos}

Los protoescólices tienen ganchos dispuestos en dos filas imbricadas; los ganchos son débilmente ácido-alcohol resistentes y su número promedio por protoescólex es de $32,9 \pm 6,9$. Se diferencian en grandes y pequeños, cada uno con un mango, una hoja y una protuberancia o talón en la zona media (figuras $8,11,16$ y 17 ).

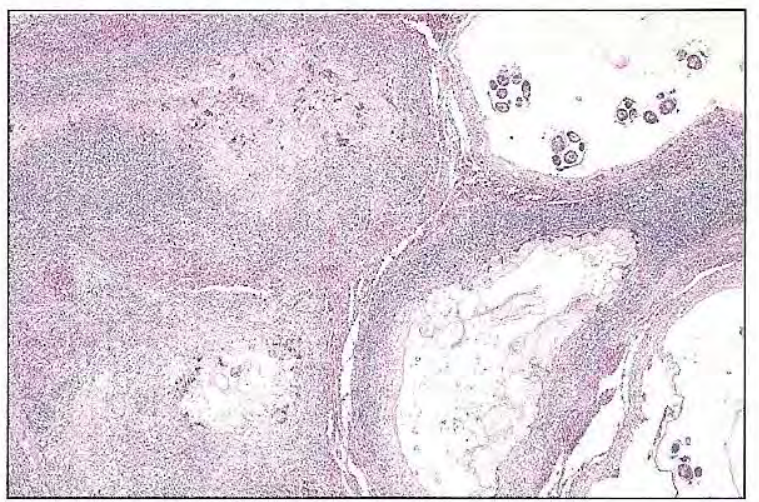

Figura 14. Bazo: imagen panorámica que demuestra extensas zonas de necrosis con inflamación granulomatosa y sólo algunos protoescólices en los quistes más claros. $\mathrm{HE}, 3 \mathrm{X}$.

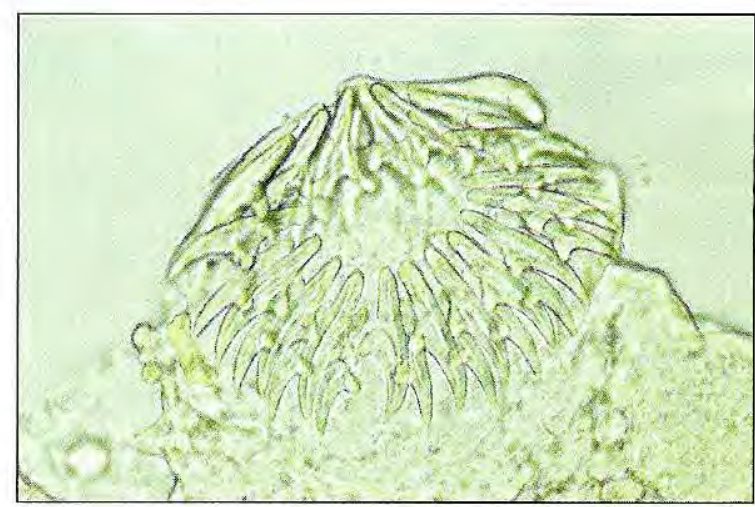

Figura 16. Examen directo sin teñir de protoescólices comprimidos entre lámina y laminilla; los ganchos están distribuidos en dos hileras y tienen tamaños largos y cortos, $80 \mathrm{X}$.
Las medidas generales de los ganchos fueron: ganchos grandes $(n=25)$; longitud total: $33,83-$ $39,38 \mu \mathrm{m}(\bar{x}=35,19 \pm 1,24)$; longitud de la hoja: $16,15-23,38 \mu \mathrm{m}(\bar{x}=21,07 \pm 1,33)$; longitud del mango: $11,73-15,31 \mu \mathrm{m}(\overline{\mathrm{x}}=13,64 \pm 0,99)$; ganchos pequeños: $(n=25)$; longitud total: $27,57-31,66 \mu \mathrm{m}$ $(\bar{x}=29,43 \pm 1,07)$; longitud de la hoja: $14,65-19,51$ $\mu \mathrm{m}(\bar{x}=16,25 \pm 1,17)$; longitud del mango: 11,62 $14,21 \mu \mathrm{m}(\bar{x}=13,16 \pm 0,76)$ (cuadro 2 ).

Para los ganchos grandes, la proporción de la hoja y el mango es de 53,13 y $45,61 \%$, respectivamente, y para los pequeños estos valores son 52,67 y $47,23 \%$.

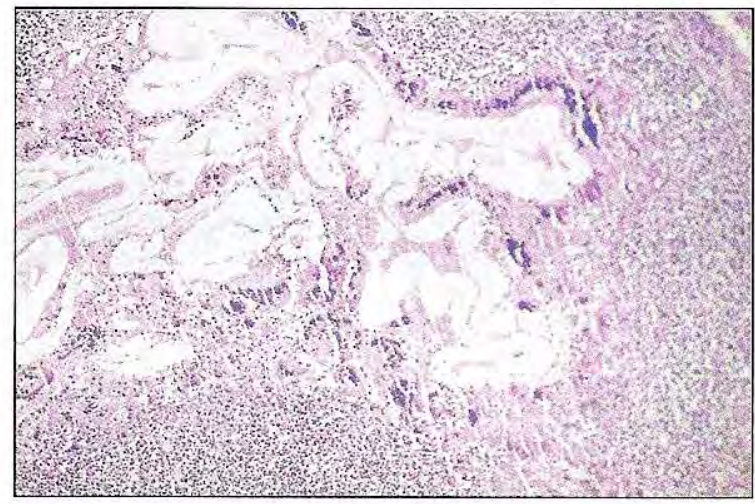

Figura 15. Bazo: membrana lamelar plegada, con aspecto festoneado característico; está intensamente rodeada por inflamación granulomatosa a cuerpo extraño. Es un estadio terminal en la reabsorción del quiste que conserva características diagnósticas, a pesar de que no se vean protoescólices. HE, 10X.

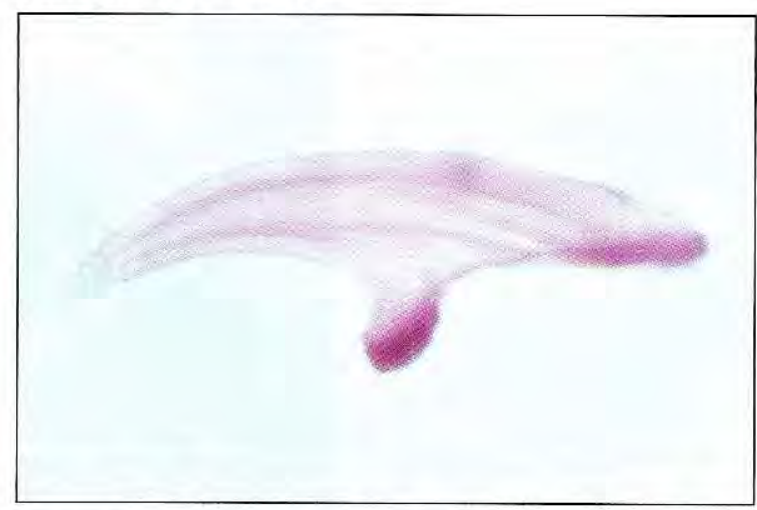

Figura 17. Gancho largo de $E$. oligarthrus, teñido para demostrar su ácido-alcohol resistencia; la protuberancia central o talón, más teñido, determina el límite entre la hoja, hacia el extremo agudo, y el mango, que es el lado opuesto. Fite-Faraco, 2.000X. 
Cuadro 2. Tamaño de los ganchos de los protoescólices de E. oligarthrus.

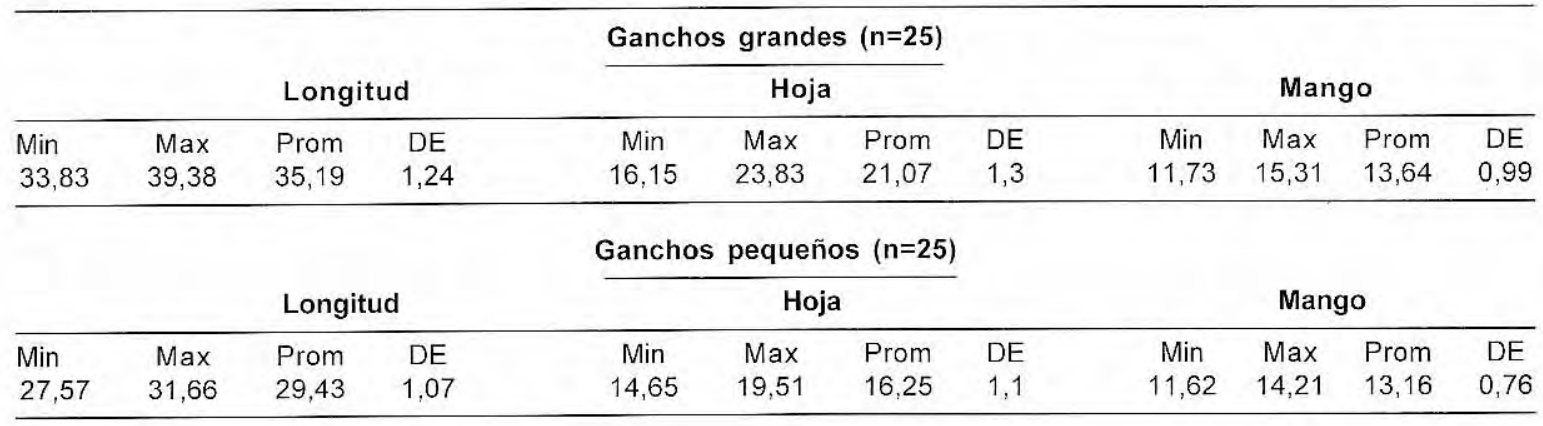

Los ganchos muestran la morfología típica de $E$. oligarthrus: largos, un poco rectos atrás y con una hoja con poco más de la mitad de la longitud total del gancho $(53,13 \%)$; el talón está situado hacia el centro del gancho (figura 17) $(3,4)$. El tamaño de los protoescólices es comparable con el descrito para esta especie (4).

\section{Discusión}

Las imágenes macroscópicas e histológicas demostradas son típicas de una hidatidosis poliquística, cuya especificación depende de muchos factores biológicos y morfológicos, entre los cuales las medidas de los ganchos son un criterio esencial. La morfología general de los ganchos, su longitud total y la relación entre la longitud de la hoja y del mango, nos permiten afirmar que la especie en estudio es $E$. oligarthrus.
Aunque las medidas de los ganchos no coinciden exactamente con las hechas por Rausch et al. (3), si se aproximan bastante y son muy diferentes a las hechas para E. vogeli, la otra especie que se consideró en el estudio de este espécimen (cuadro 3). Las variaciones encontradas pueden obedecer a diferentes grados de desarrollo de las larvas estudiadas, a diferencias intraespecíficas o a métodos distintos en el proceso de los especímenes.

La demostración de Echinococcus en especies de Proechimys es infrecuente. Entre 49 ratas espinosas sólo 2 tuvieron quistes hidatídicos, ambos de E. oligarthrus (12). Otras demostraciones de la infección por larvas de Echinococcus en estos roedores se presentan en el cuadro 4.

E. oligarthrus en su estado larvario se ha demostrado también en Cuniculus paca (paca) (3

Cuadro 3. Medidas de los ganchos de E. oligarthrus obtenidas en diferentes estudios.

\begin{tabular}{|c|c|c|c|c|c|c|c|c|c|c|c|c|}
\hline \multicolumn{13}{|c|}{ Ganchos grandes } \\
\hline \multicolumn{4}{|c|}{ Longitud } & \multicolumn{4}{|c|}{ Hoja } & \multicolumn{4}{|c|}{ Mango } & \multirow[t]{2}{*}{ Ref. } \\
\hline Min & $\operatorname{Max}$ & Prom & DE & Min & $\operatorname{Max}$ & Prom & DE & Min & Max & Prom & $\mathrm{DE}$ & \\
\hline 33,83 & 39,38 & 35,19 & 1,24 & 16,15 & 23,83 & 21,07 & 1,3 & 11,73 & 15,31 & 13,64 & 0,99 & Este estudio \\
\hline 29,5 & 37,9 & 33,4 & & & & & & & & & & 3 \\
\hline 30,9 & 35 & 33,3 & & & & & & & & & & 3 \\
\hline 27,4 & 34,4 & 32,6 & & & & & & & & & & 10 \\
\hline \multicolumn{13}{|c|}{ Ganchos pequeños } \\
\hline \multicolumn{4}{|c|}{ Longitud } & \multicolumn{4}{|c|}{ Hoja } & \multicolumn{4}{|c|}{ Mango } & Ref. \\
\hline Min & $\operatorname{Max}$ & Prom & DE & Min & $\operatorname{Max}$ & Prom & $\mathrm{DE}$ & Min & $\operatorname{Max}$ & Prom & $\mathrm{DE}$ & \\
\hline 27,57 & 31,66 & 29,43 & 1,07 & 14,65 & 19,51 & 16,25 & 1,1 & 11,62 & 14,21 & 13,16 & 0,76 & Este estudio \\
\hline 22,6 & 29,5 & 25,4 & & & & & & & & & & 3 \\
\hline 24,6 & 29,2 & 25,8 & & & & & & & & & & 3 \\
\hline 22,8 & 29,6 & 26,4 & & & & & & & & & & 10 \\
\hline
\end{tabular}


Cuadro 4. Registros de infección por Echinococcus en Proechimys.

\begin{tabular}{lcllc}
\hline Especie de Proechimys & $\begin{array}{c}\text { No. infectados/ } \\
\text { No. examinados }\end{array}$ & $\begin{array}{c}\text { Especie de } \\
\text { Echinococcus }\end{array}$ & Región & Ref. \\
\hline P. guayanensis & $4 / 0$ & E. oligarthrus & Colombia & 5 \\
P. guayanensis & $2 / 49$ & E. oligarthrus & Amazonia colombiana & 11 \\
P. guayanensis & $1 / 1$ & E. oligarthrus & Venezuela & 7 \\
Proechimys spp. & $3 / 693$ & E. oligarthrus & Llanos Orientales, Colombia & 7 \\
Proechimys spp. & $3 / 346$ & E. oligarthrus & Piedemonte de la Macarena, Colombia 7 \\
Proechimys sp. & $0 / 107$ & & Costa Pacifica, Colombia & 7 \\
Proechimys sp. & $0 / 22$ & O. oligarthrus & Panamá & 7 \\
P. semispinosus & $2 / 0$ & & & 5 \\
\hline
\end{tabular}

de 96 especímenes) y en un Dasyprocta fuliginosa (agutí) $(4,5)$. Sus huéspedes definitivos silvestres son el puma, el ocelote, el jaguar y el yaguarundi (7). Experimentalmente no infecta perros, pero sí coloniza el intestino de los gatos domésticos (5). Tal vez por esta razón su ciclo permanezca más confinado a zonas semiselváticas o selváticas, con poca ocasión de infectar a la gente, en la cual se han demostrado sólo tres casos (9-11). Un caso humano de equinococosis por $E$. oligarthrus informado en India (13) no se acepta como producido por este parásito cuyo hábitat no es propio de esta región y, probablemente, se trata de un quiste originado por E. granulosus (14). Por el contrario, E. vogeli tiene como huésped definitivo al perro silvestre (Spheotus venaticus) y es capaz de infectar a perros, cuyas heces constituyen la fuente de infección principal para la gente $(7,15)$. De acuerdo con D'Alessandro: "E. oligarthrus es mucho menos frecuente en las gentes que $E$. vogeli; ambos están presentes en zonas silvestres, selváticas y rurales. La diferencia en infecciones en la gente se debe a algunos de los siguientes factores: en las zonas rurales, generalmente hay menos gatos que perros domésticos; los gatos no acompañan a los cazadores los cuales alimentan a los perros con las vísceras de pacas en el lugar de la cacería; cuando lo hacen en la casa, las vísceras se dan a los perros y no a los gatos; los gatos entierran las materias fecales, no así los perros" (comunicación personal).

La equinococosis poliquística en la América tropical se extiende desde Nicaragua hasta Argentina, Chile y Uruguay, y su número ha aumentado notablemente en los últimos años. Se conocen en total 100 casos humanos, muchos sin publicar (15).

En Colombia, hasta 1997, se habían documentado 16 casos de quistes hidatídicos poliquísticos en humanos, la mayoría producidos por E. vogeli (15). Sin embargo, el número debe ser mayor pero no han sido publicados. Por ejemplo, tres niños de Mitú (Vaupés) han sido atendidos y diagnosticados en el Hospital de La Misericordia de Bogotá (Susana Murcia, comunicación personal) y una mujer adulta de Putumayo, fue atendida por hidatidosis pulmonar poliquística en el Hospital San Juan de Dios de Bogotá (Carlos Colegial, comunicación personal).

La descripción de E. oligarthrus aquí presentada puede hacer más fácil el diagnóstico de este parásito y su diferenciación con E. vogeli.

\section{Agradecimientos}

Este trabajo fue financiado en parte con el proyecto de Colciencias (2104-04-778-98). La ayuda brindada en la preparación de los especímenes por Marcela Neira, Diana Roa y Carlos Polanco fue especialmente valiosa. Las preparaciones de microscopía electrónica fueron realizadas por Gloria Patricia Barrera del Laboratorio de Microscopía Electrónica de CEISA, Corpoica, Bogotá. Los comentarios y sugerencias del profesor Antonio D'Alessandro fueron especialmente valiosos.

\section{Referencias}

1. Fraiji EK, Connor DH. Echinococcosis. En: Connor DH, Chandler FW, editors. Pathology of infectious diseases. Standford: Appleton and Lancher; 1997. p.1405-13.

2. Poope JB, Marcial-Rojas RA. Echinococcosis. En: Marcial-Rojas RA, editor. Pathology of protozoal and 
helminthic diseases. Baltimore: Williams \& Wilkins Co. 1971. p.635-56.

3. Rausch RI, Rausch VR, D'Alessandro A. Discrimination of the larval stages of Echinococcus oligarthrus, Diesing 1863, and Echinococcus vogeli, Rausch and Bemstein 1972, (Cestoda: Taeniidae). Am J Trop Med Hyg 1978; 27:1195-202.

4. Rausch RI, D'Alessandro A, Rausch VR. Characteristics of the larval Echinococcus vogeli, Rausch y Bernstein 1972, in the natural intermediate host the paca Cuniculus paca (Rodentia: Dasyproctidae). Am J Trop Med Hyg 1981;30:1043-52.

5. Thatcher V. Echinococcosis neotropical en Colombia y las repúblicas vecinas. Acta Médica Valle 1973;4:1727.

6. D'Alessandro A, Raush R, Cuello C, Aristizábal N. Echinococcus vogeli in man, with a review of polycystic hydatid disease in Colombia and neigboring countries. Am J Trop Med Hyg 1979;28:303-17.

7. D'Alessandro A, Raush R I, Morales GA, Collet AD Echinococcus infections in Colombian animals. Am J Trop Med Hyg 1981;30:1263-76.

8. D'Alessandro A, Vega J, Vera A. Calcificaciones quísticas del hígado en Colombia. Acta Med Valle 1970 1:3-8.
9. Lopera RD, Meléndez RD, Fernández I, Sirit J, Perera M. Orbital hydatid cyst of Echinococcus oligarthrus in a human in Venezuela. J Parasitol 1989;75:467-70.

10. D'Alessandro A, Ramírez IE, Chapadeiro E, Reis Lopes E, De Mezquita P. Second recorded case of human infection by Echinococcus oligarthrus. Am J Trop Med Hyg 1995;52:29-33.

11. Basset D, Girou C, Nozais IP, Hermies FD, Hoang C, Gordon R et al. Neotropical echinococcosis in Suriname: Echinococcus oligarthrus in the orbit and Echinococcus vogeli in the abdomen. Am J Trop Med Hyg 1998; $59: 787-90$

12. Howell RE, Schnur LF, Cadena A. Hydatid cyst in spiny rats in Amazonas, Colombia. Ann Trop Med Parasitol 1978;72:395-6.

13. Kini U, Shariff S, Nirmala V. Aspiration cytology of Echinococcus oligarthrus. A case report. Acta cytologica 1997:41:544-8.

14. D'Alessandro A. Echinococcosis in Colombia. Memorias of XV International Congress for Tropical Medicine \& Malaria. Cartagena de Indias, Colombia,agosto $20-5 ; 2000$.

15. D'Alessandro A. Polycystic echinococcosis in Tropical America: Echinococcus vogeli and E. oligarthrus. Acta tropica 1997;67:43-65. 